\section{HASTA QUE LA LEY DE DIVORCIO NOS SEPARE...}

\author{
Alejandro Sanz Romero \\ Ateneo Científico, Literario y Artístico de Madrid \\ Calle del Prado, 21 \\ 28014, Madrid \\ alejandrosanz67@telefonica.net
}

\section{TILL THE DIVORCE LAW DO US PART...}

\begin{abstract}
In 1904, due to the news published in the Diario Universal about the founding of the "club of ill-matched matrimonies", the book El divorcio en España (the divorce in Spain), saw the light. This book collected for the first time the opinion of a small but selected part of the society about a much thorny and controversial subject. Carmen de Burgos, Colombine, has asked for the collaboration, by way of referendum, not only of writers and relevant intellectuals such as Azorin, Unamuno or Pio Baroja, but also of the readers of the newspaper. The title contributed to the public renown of this authoress who was a real and passionate defender of the Law of Divorce and the Women Rights till her death.
\end{abstract}

KEY WORDS: law; divorce; matrimony; women; Diario Universal; referendum.

Desde hace siglos el hombre ha luchado, con mayor o menor fortuna, por ordenar el mundo, por definir sus comportamientos, por reglar sus vidas, por instaurar un orden social que facilitara la convivencia, por hacer justicia en defensa de la libertad y de la dignidad. Sin embargo, en España, hasta hace bien poco, algunos derechos civiles, que hoy consideramos elementales por necesarios y un verdadero signo de progreso, costó lo suyo alcanzarlos. Carmen de Burgos fue una mujer excepcionalmente moderna y progresista, en una época de nuestra historia en la que este privilegio sólo estaba al alcance de los hombres, una mujer valiente que luchó con un firme e inquebrantable compromiso ético por los derechos de la mujer en una sociedad terriblemente machista y que sufrió en carne propia, víctima de un matrimonio muy desafortunado, la exclusión y la soledad.

Carmen de Burgos se casó en 1883, con tan sólo dieciséis años y en contra de la voluntad de su padre, don José Burgos Cañizares -vicecónsul de Portugal en Almería-, con el periodista Arturo Álvarez Bustos, catorce años mayor que ella. Aunque la tesis que sostiene la gran especialista y biógrafa, Concepción Núñez Rey, es que este matrimonio
RESUMEN: En 1904, fruto de una noticia aparecida en el Diario Universal sobre la fundación de un "club de matrimonios mal avenidos", veía la luz El divorcio en España, un libro que recogía por primera vez la opinión de un pequeño pero significativo sector de la sociedad sobre un tema tan delicado como controvertido, y para el que Carmen de Burgos, Colombine, solicitó la colaboración, a modo de referéndum, no solo de escritores e intelectuales tan importantes como Azorín, Unamuno o Pío Baroja, sino de los lectores del propio periódico. Este título contribuyó notablemente a la proyección pública de nuestra autora, que fue una verdadera y apasionada defensora de la ley de Divorcio y de los derechos de la mujer hasta su muerte.

PALABRAS CLAVE: ley; divorcio; matrimonio; mujer; Diario Universal; referéndum.

se debió de llevar a cabo a finales de los años ochenta ya que su primer hijo, que vivió apenas unas horas, nació en 1890, es decir, que hubieron de transcurrir, si nos atenemos a esa fecha de enlace, siete años para su primer embarazo. Para Colombine su matrimonio fue "un episodio de ingrato recuerdo". Era comprensible que una jovencita, con ansias de libertad, sensible y con enormes inquietudes culturales, cayera en las redes ciegas del amor de una persona que era, además, escritor y periodista y que, para más inri, le dedicaba apasionados versos. En unas confesiones que hace nuestra protagonista a Rafael Cansinos Assens y que vieron la luz en La novela de un literato, confiesa que también era "un señorito juerguista", un tenorio que la fascinó y que se pasaba la vida en tabernas y garitos. De la seducción al amor y del amor, probablemente idealizado por su juventud, a la realidad más desesperante, la de un matrimonio donde no habitaba ningún afecto eterno, ni siquiera una frágil amistad.

Nuestra protagonista fue, por lo tanto, una de las muchísimas víctimas del matrimonio y de la sociedad que amparaba estas precipitadas uniones divinas y de las que era prácticamente imposible escapar, ya que como rotun- 
damente afirma el Evangelio, lo que Dios ha unido no puede separarlo el hombre. Víctima también de una sociedad mojigata, de falsa moral, en donde la mujer apenas tenía derechos jurídicos e incluso se amparaba la muerte de la esposa infiel, que a todos los efectos, se la consideraba una "menor incapaz". Recordemos, en este sentido, que con la proclamación de la Segunda República se concedió por primera vez el derecho de sufragio a las mujeres. El 1 de octubre de 1931 se aprobó en el Congreso de los Diputados, por 161 votos a favor frente a 121, el artículo 36 de la Constitución que reconocía este derecho. Artículo que habría de ser ratificado en el Parlamento el 1 de diciembre, esta vez con una votación más ajustada, 131 votos a favor frente a 127 en contra. Meses después, en marzo de 1932, se estrenó la primera ley de Divorcio, una ley, para la época y para nuestro país, muy progresista -se concedía a la mujer el derecho a tener la patria potestad de sus hijos-, aunque mejorable, ya que, por ejemplo, debía existir también el común acuerdo, y si no, la alegación, de una larga lista, del motivo de divorcio, tal como la bigamia, el adulterio no consentido, la prostitución de los hijos o de la mujer, el abandono del cónyuge durante un año, etc. Otra de las razones, tan importantes como las mencionadas, era no cumplir con las obligaciones matrimoniales: cuando no ha habido cópula carnal entre los esposos, por enfermedad contagiosa y grave, por condena o por enajenación mental. Con la ley de Divorcio actual, la segunda en nuestra historia, la de 1981, no hay que alegar razones para divorciarse.

Carmen de Burgos optó por liberarse del yugo matrimonial -cuando el matrimonio era la única "carrera" a la que podía aspirar fácilmente una mujer- de la única forma que era posible, a través de una formación académica que le otorgaría independencia económica. Es así como obtiene el título de maestra y como consigue abandonar, en compañía de su pequeña hija, su ciudad natal y trasladarse a Madrid donde empezaría a destacar como escritora y periodista.

En 1903 comienza a trabajar en el nuevo Diario Universal, que dirige Augusto Suárez de Figueroa, bajo el pseudónimo de Colombine, que hace referencia a uno de los personajes, el más sensato curiosamente, de la Ilamada Comedia del arte. Se convierte asi en la primera mujer que escribe una columna fija en un periódico. Esta columna se titulaba "Lecturas para la mujer", y en ella hablaba de temas de corte femenino, como la moda o la maternidad. En diciembre de este mismo año aparecía en este espacio la siguiente noticia:

Me aseguran que en muy breve se fundará en Madrid un "Club de Matrimonios mal avenidos", con objeto de exponer sus quejas y estudiar el problema en todos sus aspectos, redactando las bases de una ley de divorcio que se proponen presentar en las Cámaras.

A raíz de esta información y de algunas cartas enviadas a nuestra redactora, en donde manifiestan poco menos que asombro por la noticia, Colombine decide, a partir del 20 de enero, empezar a publicarlas; aunque la verdad es que muy pocas vieron la luz en el propio Diario Universal, apenas una docena. El 15 de marzo se vio forzada, por distintas presiones y ataques, a suspender el plebiscito en el diario y a anunciar que todos los textos que recibiera verían la luz en un libro, tal como sucedió. La Iglesia se puso en su contra ya que consideró que atentaba no sólo contra un sacramento divino, sino contra la mismísima familia, y los sectores más reaccionarios e intolerantes llegaron incluso a aplicarle el apelativo de "la divorciadora".

Carmen recordaría, muchos años después, en 1916, en una entrevista con José M. ${ }^{a}$ Carretero, el Caballero Audaz, que su obra más combatida fue El divorcio en España "porque es la que atacó más directamente la gazmoñería, la mojigatería y la beatería ambiente".

La publicación de este libro supuso, a pesar de todo, no sólo la proyección pública y popular de Carmen, sino un verdadero acontecimiento social, no exento de polémica, que originó un encendido debate. Por primera vez los españoles, una parte muy reducida pero significativa de la sociedad, se pronunciaban abiertamente sobre una cuestión tan delicada como el divorcio. Carmen de Burgos invitó a lo más granado de la intelectualidad española a pronunciarse sobre el tema, pero también lo hicieron muchos lectores del Diario Universal.

El libro recoge dos bloques de opiniones, las solicitadas por la propia Colombine, y las recibidas por sus lectores, así como una conclusión de la recopiladora, que es todo un manifiesto donde no queda lugar para la ambigüedad: "El divorcio es un signo de progreso, está admitido en la 
mayoría de los países y es conveniente a la sociedad y a la moral". En el primero de los bloques o partes se dan cita nombres importantísimos de la cultura española, escritores como Azorín, Unamuno, Pío Baroja, Jacinto Octavio Picón, Emilia Pardo Bazán o Vicente Blasco Ibáñez, políticos como Raimundo Fernández Villaverde, Antonio Maura, Gumersindo de Azcárate, José Canalejas o Francisco Silvela, o ilustres pedagogos como Francisco Giner de los Ríos -fundador de la Institución Libre de Enseñanza-. La mayoría de los colaboradores de este pequeño pero intenso referéndum se define abiertamente a favor del divorcio, aunque hay quien elude diplomáticamente pronunciarse sobre el tema, gran parte de ellos, políticos. La razón que incide clara y principalmente en algunas de las reflexiones u opiniones contra el divorcio no es la jurídica, sino la religiosa. No hay que olvidar que España navegaba más que en las limpias aguas del laicismo en las del más oscuro catolicismo. Los creyentes no pueden aceptar la disolución por el hombre de un contrato firmado ante los ojos de Dios. Sorprende también que algunas de las opiniones vertidas contra el divorcio provengan de mujeres - pocas- con un increible, por elevado y absurdo, concepto del sacrificio. No puedo dejar de referirme, por tentadora, a la justificación que arguye contra el divorcio la escritora y compositora

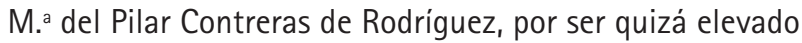
arquetipo de la rancia moral católica de la época. Esta señora llega a decir:

el matrimonio debe considerarse como el acto más trascendental de la vida y nunca como medio de especulación, de negocio, o como pueril satisfacción de la vanidad o del capricho.

Al hombre toca, principalmente, poner los medios para ello, toda vez que él tiene la facultad de elegir, pues la mujer ha de contentarse con el marido que le depare su suerte, y ya dijo un conocedor profundo de ella, que no tiene más historia que casarse. [...]

Por grande que sea, sin embargo, el abismo que separe dos almas dentro de un mismo hogar; por inmensa que sea la desdicha de dos seres que viven unidos hasta la muerte y se odian y se repudian de una manera profunda e implacable, la dicha que proporcionan los hijos y los encantos de que rodean la existencia, tienen poder suficiente para contrarrestar todos los sinsabores que trae consigo la desavenencia conyugal. El amor de los hijos en este caso viene a ser como dulce lenitivo que suaviza las asperezas de los más intensos pesares, como manantial purísimo que regenera el espíritu, alejando de él las dudas, los odios y los temores; como alegre rayo de sol que, abriéndose paso entre las nubes, ilumina dulcemente el paisaje ensombrecido por pesadas nieblas (Burgos, 1904, 35-36).

Es decir, que el mágico encanto de los hijos -ni siquiera habla de niños, y suponiendo que se tengan-debe eclipsar cualquier odio, violencia, infidelidad, maltrato físico o psicológico, porque quien ha confesado su amor ante Dios, no tiene derecho a librarse del infierno del matrimonio cuando ese amor ya no existe.

Entre las variadas opiniones de las lectoras del Diario Universal, no faltan también disparates como el referido. Así, una tal Farinata, cree que lo oportuno frente al desamor, en el mejor de los casos, es invocar en sentido figurado al santo Job hasta que el no menos santo Dios decida:

No negaré que existan maridos con los cuales se hará insoportable la vida; también es evidente que algunas esposas convierten el hogar doméstico en un infierno; pero cuando esto suceda, me parece mejor que, armados de paciencia, abnegación y tolerancia, esperemos resignados a que Dios se sirva cortar el estrecho lazo del matrimonio con la muerte de uno de los cónyuges.

No es posible que la mujer encuentre la dicha al lado de otro hombre después de haber anulado su matrimonio con el padre de sus hijos, ante los cuales tiene que encontrarse muy pequeña por el anatema de degradación que la mayor parte de la humanidad lanzará sobre ella (Burgos, 1904, 104).

Espléndida solución: imaginen a una joven y desafortunada esposa que ha llegado al matrimonio por alguno de los insondables caminos del Señor y que, iluminada por la patética realidad de su esposo, quince, veinte o treinta años mayor que ella, reza incansablemente en la hermosa soledad del hogar, mientras amamanta a su hambrienta prole, para que cuanto antes lo tenga en su gloria. Pero Dios sólo recibe la llamada de la ingrata y abnegada esposa cuando ya es tarde para rehacer su vida.

Afortunadamente, la mayoría de los consultados hace uso del sentido común y justifica con incuestionables y hasta originales razonamientos la necesidad de una ley del Divorcio. Vicente Blasco lbáñez responde a la consulta de Colombine decantándose contundentemente a favor del 
divorcio, por la misma razón que cree en el amor y no en el matrimonio:

La bendición del sacerdote, el acta del juez, las convenciones sociales, son invenciones humanas de las que se rie el amor, eterno y caprichoso soberano del mundo imaginado por todas las mitologías, como un dios voluble y tornadizo.

Cuando el amor se aleja para siempre, ¿a qué empeñarse en mantener la ligadura del matrimonio entre dos seres que se odian o se desprecian, como los presos que amarrados por la misma cadena han de satisfacer en común las más groseras necesidades?

Sin el amor no debe subsistir la asociación del hombre y la mujer, por más bendiciones que la santifiquen y leyes que la protejan.

Los seres sanos y fuertes, cuando no se aman, deben decirse adiós, sin pena y sin rencor, emprendiendo distintos caminos para rehacer de nuevo su vida (Burgos, 1904, 14).

Aunque quien sostiene uno de los planteamientos más originales, sencillos e irrefutables en defensa de la ansiada ley, es la propia Carmen de Burgos, que también responde a la consulta con un artículo que hace oportuna referencia a la reforma en las Órdenes religiosas promulgada por el Papa Pío X, precisamente en 1904, y en la que los votos religiosos dejaban de ser perpetuos, pudiendo romper la clausura las monjas arrepentidas. Y formula, al hilo de esta nueva norma de la Iglesia, la pregunta idónea para los propios católicos, estableciendo un paralelismo entre lo divino y lo humano: "si se permite el divorcio con el esposo perfecto, ¿qué razón hay para no permitirlo a las esposas de los simples mortales?". Observen además que en este tipo de divorcio, realmente progresista para la Iglesia, no es ni siquiera necesario el mutuo acuerdo, ni la infidelidad. La manifestación de renuncia viene sólo de una parte, porque de venir de las dos, o de la más alejada terrenalmente, nos hallaríamos ante un milagro.

No faltan tampoco en el libro al que estamos refiriéndonos algunas viscerales manifestaciones, que hoy, con la perspectiva que ofrece el tiempo y la historia, no dejan de ser grotescas y patéticas, pero que en aquel entonces podian ser reflejo del sentir de una parte, la más intolerante e iluminada, de la beatería nacional. En las "opiniones de los lectores" una tal Daría Bünsen -probablemente pariente de Torquemada- se queda tan ancha al afirmar que "todos los que piden el divorcio, o son unos insensatos, neurasténicos e histéricas, o son seres depravados, que merecen se les fustigue para que, ya que no aportan a la sociedad ningún átomo de bondad y pureza, al menos no se entrometan en el ambiente común, con escándalo, y hasta con sus dejos de escuela, el virus de una prostitución sorda y verdaderamente aborrecible" (Burgos, 1904, 100).

De una mujer católica, según confiesa, pero partidaria del divorcio vienen también estas consoladoras opiniones: "recordemos las palabras de Santa Teresa de Jesús: 'El infierno es un sitio donde no se ama'. Y el infierno puede existir entre los casados a perpetuidad, y el amor entre los divorciados y casados de nuevo".

Tampoco faltan en El divorcio en España momentos para la ironía y el humor negro, como los del célebre y prolífico escritor, periodista y humorista, Juan Pérez Zúñiga, que defiende el divorcio, pero con unas extravagantes condiciones:

si el hombre es el que falta [al sagrado sacramento] debe establecerse la libertad legal de los cónyuges para contraer nupcias, y debe señalarse además para el marido una pensión, procedente del trabajo de la mujer; más si es ella la culpable, el hombre debe asesinarla sin contemplaciones de ninguna especie. Con esto se conseguiria, por regla general, la separación de los esposos y la libertad del superviviente. En caso de haber hijos, la cuestión se hace más delicada, y creo que si los padres los quieren de veras, la vispera del divorcio, a la caída de la tarde, deben asesinarlos también. Es una solución que tiende a la simplificación de las familias y a la evitación de amarguras ulteriores (Burgos, 1904, 77-78).

Entre los más argumentados e irrefutables textos sobre el tema que se plantea, Alfredo Calderón -colaborador del diario La Publicidad de Barcelona-, se formula una larga serie de preguntas, no sin antes manifestar que lo primero que hay que hacer es descartar el prejuicio religioso, porque "desde el momento en que se asegura que el matrimonio es un sacramento, ya no hay forma de comprender qué cosa el matrimonio sea". Para nuestro escritor, el divorcio, al margen de su ejecución práctica, es un hecho en una amplia cantidad de hogares, en los que los consortes sobreviven "amarrados al yugo" y "cuya existencia es un infierno". Por lo tanto, cómo hay que actuar ante esa terrible realidad, en la que la mujer está más desprotegida. Y se pregunta: 
¿Desconocerla? ¿Negarla? ¿Reemplazarla por sus convencionalismos consuetudinarios o jurídicos? ¿Proclamar la existencia de lo no existente y la efectividad de un fantasma? ¿Convertir la vida entera en expiación de la equivocación de un dia? ¿Declarar al error irremediable e irremediable al extravío? ¿Transformar la santa unión matrimonial en cadena de forzado? ¿Cerrar para siempre ante el que erró las vías de la rehabilitación y los caminos de la dicha? ¿Trocar lo que es ensueño de ventura en instrumento de suplicio y dar al infierno nombre de paraíso? ¿Para defender los fueros de la mujer condenarla a infelicidad de por vida? ¿Para velar por el interés de los hijos, obligarles a ser testigos de las querellas de sus padres? ¿Invertir las relaciones entre el derecho y la vida, sometiendo la realidad a la ficción y sustituyendo a la verdad las apariencias?

Muchas preguntas y sólo una respuesta coherente a todas ellas: no. Un "no" que autoriza el divorcio.

Partiendo de la base de que las leyes han de estar al servicio del bienestar de los ciudadanos, al margen de sus creencias políticas o religiosas -si las hubiera- y del progreso de la sociedad en la que viven, no cabe duda de que el principal obstáculo en el desarrollo de la ley de Divorcio fue la propia Iglesia, que es quien por otra parte tenía, lo que hoy podríamos llamar, el derecho de marca.
Sólo a partir de junio de 1932 se instauró de nuevo el matrimonio civil obligatorio para todos los contrayentes -ya se había aprobado uno en 1870-, declarándose que la jurisdicción civil era la única competente para resolver, entre otras cosas, la validez o nulidad de los matrimonios canónicos anteriores a la vigencia de esta ley. A partir de entonces los tribunales eclesiásticos no pudieron interferir en las resoluciones de naturaleza civil.

Carmen de Burgos fue, como queda demostrado por sus acciones y por la publicación de El divorcio en España, una infatigable defensora de los derechos de la mujer. Su experiencia directa, como víctima de un mal matrimonio y de una sociedad rancia, primitiva y anquilosada, de la que aún conservamos muchos de sus defectos más indelebles, se vio también reflejada en distintas obras de creación como La Rampa (1917), La malcasada (1923) o La que se casó muy niña (1923). Su fracaso emocional probablemente fortaleció su interés ante una causa tan necesaria, porque sólo los espíritus románticos e idealistas se crecen en la adversidad, sople el viento que sople. Porque hoy existe una ley de Divorcio, de la que se benefician no sólo las mujeres, sino la sociedad entera, hemos de recordar con agradecimiento la labor de Carmen de Burgos, que afortunadamente, pocos meses antes de morir, el 9 de octubre de 1932, vio cumplido su sueño. 